\title{
The Acquisition of Polysynthetic Languages
}

\author{
Barbara Kelly, Gillian Wigglesworth, Rachel Nordlinger* and Joseph Blythe \\ University of Melbourne, Australia
}

\begin{abstract}
One of the major challenges in acquiring a language is being able to use morphology as an adult would, and thus, a considerable amount of acquisition research has focused on morphological production and comprehension. Most of this research, however, has focused on the acquisition of morphology in isolating languages, or languages (such as English) with limited inflectional morphology. The nature of the learning task is different, and potentially more challenging, when the child is learning a polysynthetic language - a language in which words are highly morphologically complex, expressing in a single word what in English takes a multi-word clause. To date, there has been no cross-linguistic survey of how children approach this puzzle and learn polysynthetic languages. This paper aims to provide such a survey, including a discussion of some of the general findings in the literature regarding the acquisition of polysynthetic systems.
\end{abstract}

\section{Introduction}

Children in all cultures grow up learning language. By the age of 5 years, they can communicate effectively in their native language or languages, although they still have a considerable amount to learn. ${ }^{1}$ Learning the morphology of a language is a difficult task even for languages with small amounts of morphology, and as a result, considerable acquisition research has focused on morphological production and comprehension, although some work has addressed more macro-level acquisition of discourse structure (Allen 2007; Allen and Crago 1992).

Much of the literature has highlighted the challenges for learners. In Brown's (1973) seminal research on the acquisition of morphology in English, he showed that semantic and formal complexity (on the basis of his own intuition) are causally related to the acquisition of morphemes and the development of more complex constructions. However, languages vary enormously in terms of their morphological structures, and it cannot necessarily be assumed that the challenges for learners, and the processes by which morphology is acquired, hold across all morphological types. Consequently, the key questions which need to be addressed in the field focus around issues of salience, the impact of language type, and morphological complexity. In this paper, we review the limited literature, which relates to these questions.

It is common in morphological typology ${ }^{2}$ to categorize languages in terms of the amount of obligatory morphology - the morpheme to word ratio. Isolating or analytic languages fall at one end of this continuum, having few or no bound morphs. These ratios are very low (1:1 in the extreme) such that each morpheme constitutes an independent word. Vietnamese is often cited as such a language. Since this is a continuum, many languages fall somewhere in the middle, with languages like English falling towards the isolating end of the continuum, with some bound morphology, albeit rather limited. Synthetic languages fall at the other end of this continuum, with high morpheme-to-word ratios and therefore greater morphological complexity.

Polysynthetic languages represent the extreme end of this continuum. Polysynthetic languages achieve very high ratios through both agglutination and fusion (discussed further 
below). These languages are capable of expressing all arguments morphologically, so that a single verb can express what would in English take a multi-word clause (Evans and Sasse 2002, also Baker 1996). The processes involved might include pronominal affixation, the incorporation of nouns for arguments, direct sub-categorization of arguments in the root, or use of applicative affixes.

Among the languages that fall toward the synthetic end of the continuum (including polysynthetic languages), we can distinguish agglutinating languages at one end of a continuum from fusional languages at another. ${ }^{3}$ Agglutinating languages are those in which we find a clear separation of bound morphs such that each morph has one meaning and a clearly identifiable form. Swahili (and other Bantu languages) is a classic example of this morphological type. In fusional languages, there is no simple one-to-one correspondence between morph and function, such as in Greek and Latin.

In terms of acquisition research, much of the focus on the acquisition of morphology has been on languages that fall more toward the isolating end of the continuum, such as English, and there has been comparatively little work examining the process by which children learn synthetic languages, especially polysynthetic languages, yet we may hypothesize that the learning task may be substantially more challenging in these cases.

This is an area, therefore, which cries out for investigation. In 1989, Mithun noted that opportunities for studying the acquisition of polysynthetic languages are diminishing due to language death and that '[t]here is much to discover in little time' (1989: 286). Two decades later, this is even more imperative since many of the world's polysynthetic languages are either endangered [e.g. the North American language of Dene Suliné - Chipewyan (Rice, Libben, and Derwing 2002)] or are under threat [e.g. the Australian language Murrinh-Patha (Kelly, Nordlinger, and Wigglesworth 2010)]. As Evans and Levinson argued, to fully understand language processing, we must understand how children learn languages with structures that 'vary in every possible dimension' (2009: 431) and how greater knowledge of this might contribute to what we understand about the potential universals that children bring to the task of language learning.

For children, learning a morphologically complex, polysynthetic language resembles a great big jigsaw puzzle with no picture key. Peters (1997), in a discussion of the ease or difficulty for children in learning different languages, asked how is it possible for children to acquire West Greenlandic at all. This is because West Greenlandic is a highly polysynthetic language with over 300 inflectional affixes, and a further 4-500 derivational affixes, all bound morphemes, which children appear to acquire between the ages of 2 and 5 years (Fortescue and Lennert Olsen 1992).

To date, there has been no cross-linguistic survey of how children approach this puzzle and learn polysynthetic languages. This paper aims to provide a brief overview to some of the general findings regarding the acquisition of polysynthetic systems. Given the small amount of available research in this area, we also draw where relevant on acquisition research focusing on other synthetic languages such as Bantu languages (e.g. Deen 2005; Demuth 1992). Although not technically polysynthetic in the sense of Evans and Sasse (2002), these languages typically have high morpheme-to-word ratios and so present many of the same morphological challenges to the language learner.

\section{Acquisition of Complex Morphology}

It is no surprise that polysynthetic languages have not been the subject of much acquisition work, given that so few are adequately described even from an adult usage perspective. Indeed, much of the language description work, and particularly the acquisition research, 
on polysynthetic languages focuses around how these fit into or support theoretical linguistic positions of innateness and universality, since their complexity provides opportunities to assess cross-linguistically what appears to be universal about acquisition, and what is language-specific.

For example, Baker (2001: 655) noted that the existence of such languages 'forces one to ask how is it that human linguistic capacities are articulated enough to account for the ease of language acquisition and yet flexible enough to generate languages that are superficially so different'. This review will not engage with the debate about how these languages are learned, rather it will describe how researchers have presented the unfolding of morphology in the language production of young users and some of the more relevant questions the research raises. The studies reported here are drawn together because they focus on complex morphology in acquisition. The selected studies are not intended to be exhaustive but rather to represent work across a broad array of morphologically complex languages. The majority of these studies are investigations of specific morphemes, and each has different foci with little overlap in the specific areas of investigation. All engage briefly with how the language fits with reported underpinnings of word learning, so we begin with a brief look at theories of lexical acquisition.

\section{I. THEORIES OF WORD LEARNING}

Much of the acquisition research that describes or explains how children come to learn new words, along with all their attendant morphology, takes one of three positions: (1) there are constraints on lexical acquisition related to relationships between words and other features, which may be associated with a specialized language-learning faculty (Carey 1978; Gleitman 1990); (2) word learning is part of the ongoing development of general cognitive capacities (Bloom 2000); and (3) word learning is an integral part of social interaction and is mediated through spontaneous everyday conversation (Tomasello 2000). Regardless of the position taken, an implicit assumption in this research is that cognitive-based findings regarding more isolating languages are likely to hold across all languages, despite the fact that many of the world's languages are vastly different in prosodic structure, lexical forms and especially the notion of what constitutes a word. For example, in isolating languages, memorization and rote learning may play a substantial role, but the role of memorization may be less helpful in polysynthetic languages given the sheer magnitude of stems, affixes, and endings that combine in myriad ways (Fortescue and Lennert Olsen 1992).

The role of perceptual salience (sometimes used interchangeably with phonological salience) is often discussed in research examining early language; however, the term is rarely defined and is often used as an umbrella term for both phonological prominence (stress) and parseability of a string given that morphemes at word-boundaries are more easily parsed by listeners regardless of their perceptual salience. ${ }^{4}$ Perceptual salience is the ease of processing of acoustic properties by the human auditory system (Leonard, McGregor, and Allen 1992) whereby syllables with primary or secondary stress are more noticeable than their unstressed counterparts, and are considered more salient to children in the early stages of language learning resulting in the earlier production of stressed syllables. Pye (1992) suggested a broader account including frequency of input, syllabicity, stress, and position in the utterance (1992: 259). De Jong, Beckman and Edwards (1993) have shown a correspondence between stress and hyperarticulated speech production, which they argued leads to higher clarity of parsing and perception by the listener. Peters $(1983,1985)$ has shown that initially, children may rely more heavily on perceptual salience around prosodic structures in their early learning. 
Research into morphological acquisition is heavily focused on Anglocentric baselines such as Brown's (1973) groundbreaking research into the acquisition order of the first 14 morphemes in English. Similar orderings have been attested cross-linguistically suggesting that this approach works well for analyzing more isolating languages. While there is still some debate regarding the cognitive versus linguistic and social accessibility of such morphemes (e. g. Larsen-Freeman 2007), one area that would benefit from further investigation is the acquisition order of these morphemes in more complex languages. As already noted, because there is not a lot of comparable data across the small number of polysynthetic acquisition studies, acquisition order is not a useful means of presenting the data. Instead, although somewhat artificial, since some researchers focus their study on languages within loosely similar geographical locales (e.g. Courtney and Saville-Troike 2002; Strömqvist and Ragnarsdóttir 2000), geographical boundaries form the framework here for investigating polysynthetic first language acquisition.

\subsection{CROSS-LINGUISTIC STUDIES}

Studies in this overview include acquisition of forms in languages of North, Central, and South America (Mohawk, Navajo, Tzeltal, Quiché, and Quechua), as well as Eskimo-Aleut languages (Inuktitut, Greenlandic) and Bantu languages (Sesotho, Siswati, Swahili). While not all of these languages may be considered polysynthetic, they are all highly morphologically complex, which warrants their inclusion in this discussion. Many of the studies incorporate longitudinal data, but typically for only a small number of children. While there is little direct comparability across the studies, patterns in results are evident across several of the studies and will be discussed below. ${ }^{5}$

\subsubsection{Languages of the Americas}

In this section, we focus primarily on key studies of the acquisition of Mohawk, Quechua, Navajo, Tzeltal, and Quiché. There have also been some studies on the acquisition of Cree dialects, including Oji-Cree (e.g. Upper and McKay 1987, 1988) and North-Eastern Cree (e.g. Brittain et al. 2007; Terry 2010; Rose and Brittain 2011), but space precludes discussing these in further detail here.

\section{Mohawk}

Mithun (1989) studied the acquisition of Mohawk across five children aged around 1;9-4;9. She found that their earliest meaningful productions were segments of full words at a phonological level, independent of the morphological status of the syllable. Primary word stress in Mohawk is usually penultimate, and children produced penultimate stressed syllables first or moved leftward to the antepenultimate syllable if this was stressed. For example, a child aged 1;9 produced ' $t$ i for the adult form sa'tita 'get in' (Mithun 1989: 292). Coda syllables were then added, confirming importance of the ends of words (see Bloom 2000 for discussion of similar findings in English).

This leftward movement leads the child next to the discovery of a system of pronominal prefixes. At this stage of production, distinctions expressed by adults in affixes were either omitted or expressed analytically, external to this word. Mithun concluded that when utterances were complex enough to include pronominal prefixes as well as roots, the child was ready to move on to the acquisition of the morphological system as distinct from the phonological system. 
In the adult language, children hear pronominal prefixes in nearly every utterance, and so they serve as a good measure for determining the onset of morphological development. Mithun noted that perceptual salience appears key to the beginnings of the acquisition process.

\section{Quiché}

In research on Quiché (K'iche Maya in Pye 1992), a Mayan language spoken in Guatemala, Pye $(1980,1992)$ was also interested in perceptual salience and the role it plays in determining the order of acquisition of separate morphemes. In his study of the language use of two children aged 2;0 to 4;0, Pye focused on the order of acquisition of the set of prefixes, which mark the person/number of the core arguments of the verb.

As with Mohawk, Quiché Mayan displays a complex system of verbal inflection. In the active voice, prefixes to the verb root/stem mark five categories of tense-aspect-mood and subject/object person/number agreement. If a verb is derived from a noun or adjective, a transitivizing suffix is affixed to the root to form the verb stem. This results in a highly complex verbal predicate for the child to unravel. Focusing on the semantic complexity of the prefixes, Pye found that there was no correlation between predictions about the order of acquisition on the basis of complexity (i.e. less to more semantically complex) and the order of acquisition. The child's earliest utterances were always monosyllabic, such as the demonstrative $l e$, and uses followed a prompt of a stressed syllable from the adult speech regardless of where in the word that syllable fell, or the semantic context of the syllable. He did, however, find a relation between the early acquisition of person markers which fall wholly within a stressed syllable, as opposed to those that straddle syllable boundaries suggesting that, as with Mohawk, perceptual salience provides the underpinning of the acquisition process in Quiché.

\section{Tzeltal}

Tzeltal is a mildly polysynthetic Mayan language spoken in Mexico. Tzeltal sentences consist of verbs and associated morphology - roots plus ergative and/or absolutive marking plus aspect marking. The lexicon has a small number of roots with productive derivational morphology. Much of the derivational morphology applies to both nouns and verbs, except only verbs take obligatory aspect marking. Brown (1998) in a study of verb development in children aged 1;4-2;6 noted that while the language is potentially obfuscating, children tend not to have issues learning the noun/verb distinction, and she posited that this is due to regularity of derivational morphology and large scale distributional properties. Roots are often identified by an adult via a convention of conversational repetition, as seen in example (1) below where Slus, aged almost 2;6 converses with an adult:

(1) Slus Adult $\mathrm{k}-\mathbf{i c h}$ 'ja ini (I get this one) ya 'w-ich ini (you get this one)

\section{(Brown 1998:51)}

Productivity appears to be reached early (before children have a Mean Length of Utterance (MLU) of 2.0), at least for certain morphemes such as absolutive suffixes, as well as the vowel-initial ergative cross-referencing affixes, which indicate the basic argument structure of their verbs, and morphemes appear to be used correctly before children reach 2;6 (Brown 1998:743). Brown argued that the improved productivity of the vowel initial affixes over consonant-initial affixes is a result of the salience of the former.

Brown (1998) discussed her findings in relation to the research showing noun dominance in Indo-European children's language, which has been said to occur because of the concrete nature of nouns. However, research on non-European languages shows that this noun 
dominance may be language-specific and that there is an 'early verb explosion' in nonIndo-European languages (e.g. Korean). Brown also pointed out that input may play a role here: not only do Tzeltal caregivers not engage in object naming routines, but also the child is more likely to be asked 'What are you doing?' than 'What is that?'

\section{Quechua and Navaho}

Courtney and Saville-Troike (2002) investigated morphological development and the verbal complex in Quechua and Navajo; both of which have rich morphology. The language development of four Quechua-speaking children, aged 2;0 to 3;5, from an Andean community in Peru was examined. They were recorded over a 5 -month period. The Navajo data were collected from five Navajo-speaking children aged 1;1 to 4;7 living in Arizona, over a 2-year period.

In opposition to Quechua, Navajo verb roots are word final. Despite these typological differences, the researchers found that even though adult input had forms consisting of two to six morphemes, but never bare stems, the youngest children in both languages extracted and produced bare stems, but never did so with isolated affixes. In Navajo, where stems generally are single syllables, the children omit prefixes carrying semantic information even when they are in a perceptually salient position. In Quechua, children omit perceptually salient open syllables.

Where prosody is concerned, both languages have the stem/root at the periphery of the verb, which may assist identification, although the primary prosodic cues differ (tone in Navajo, word stress in Quechua). Courtney and Saville-Troike (2002) pointed out that, given the perceptual salience of some affixes, some children could be expected to produce bare affixes, but as mentioned above, they never do. Quechua children both hear and preferentially produce monosyllabic allomorphs. Navajo children are not likely to hear monosyllabic morphemes since well-formed verbs in Navajo cannot normally be monosyllabic. However, both Quechua and Navajo children produce roots/stems before acquiring affixes, irrespective of whether they carry primary stress. For example, Courtney and Saville-Troike (2002: 635) illustrated with the following examples. A Quechua speaker Ana, aged 2;5-2;6, produced the bare root for 'muna' (want) and for 'qan' (2 person) 'chay muna qan' (you want that) where the adult target is

(2) chay-ta muna-ski qan that-ACC want-2sub 2pro

The Navajo learner, Norah, at 1;1 produced the bare stem ' $d a$ ' (sit) for the adult form of ní-d'aah 'you sit'.

(3) ní-d'aah theme/2sub-sit

This suggests that their acquisition does not follow through from word-specific paradigms to generalized patterns of inflection. Note that, as Courtney and Saville-Troike pointed out, this pattern of acquisition differs from that in Quiché and Mohawk, where early verb forms consisting of the stressed syllable are initially extracted, regardless of whether it is the root/ stem. The acquisition patterns also follow findings for Inuktitut (e.g. Crago and Allen 1998). Courtney and Saville-Troike (2002) concluded that their findings for acquisition in Navajo and Quechua indicate that inflection cannot be a completely top down process.

In relation to how children learn accuracy of morpheme order, as we will see in Deen's (2005, 2006) findings for Swahili, Navajo children never made errors in sequencing, and 
neither did the three youngest Quechua speakers. However, more proficient Quechua speakers and adults (i.e. productive users of the language) did make sequencing errors.

\subsubsection{Eskimo-Aleut Languages}

Turning now to studies of Eskimo-Aleut languages, the primary research on these polysynthetic languages has been work on Inuktitut and Greenlandic. In their research on the acquisition of Inuktitut, Allen and Crago (1992) and Allen and Schröder (2003) provided discourse related explanations for the patterning of acquisition, in particular, of argument structure and causatives. Several of the patterns highlighted have been noted in West Greenlandic and Greenlandic, which are geographically similar polysynthetic languages (Fortescue 1985; Fortescue and Lennert Olsen 1992; Strömqvist and Ragnarsdóttir 2000).

\section{Inuktitut}

Allen and Crago (1992) and subsequent work by Allen (1995, 1996, 1998, 2007) has gone beyond looking at the acquisition of noun and verb categories and focused on how smaller verbal categories are learned. In particular, Allen's research and Allen and Schröder's (2003) study looked at the acquisition of argument structure in extended discourse, as well as the acquisition of the causatives. In Inuktitut, causation can be expressed via two means, one analytic and one lexical. There are two verb categories for causatives; one has a morphological causative, and one takes either a lexical or morphological causative depending on the semantics. Allen and Schröder's (2003) study focuses on how and when children learning Inuktitut learn to categorize verbs into the two classes. The study used spontaneous speech data from two longitudinal studies of eight children aged $1 ; 0-3 ; 6$, across two monolingual communities in arctic Quebec.

In a study of Inuktitut causative acquisition, Allen $(1996,1998)$ found three stages of use. At stage one (children aged 1;0-2;8), children showed no understanding of morphological causatives and did not use them, but showed some rudimentary understanding of lexical causatives. Allen suggested that children are not likely to have understanding of verb categorization at this stage. At stage two (children aged 2;0-2;9), morphological causatives are used, but not in the adult form, as they either have no inflection, no verb root, or are used in fixed form, as seen in (4) below where Lizzie, aged 2;6, is asking her mother to do something for her but omits the verb root:

(4) tilaurak

tit-lauq-guk

CAUSE-POL-IMP.2sS.3sO

'Make it do X'

(Allen 1996: 102)

The morphological causatives used at this stage are all imperatives or first person suggestions. Lexical causatives are used with a range of frequently used verbs. Allen noted some productivity for this category, but verbless forms also appear, so she concluded that children are still not sure which verbs need morphological causatives and which need lexical causatives. At stage three (where children are 3;1-3;6), children used the forms in an adult-like way (although two children over-generalized at this period).

Allen (1998) concluded that acquisition of these forms in Inuktitut follows patterns seen for English and Hebrew, where children first use unanalyzed chunks. Additionally, she noted verb-by-verb learning, and a pattern of learning consistent with a phasal view of acquisition 
in which children go through well-defined general stages in their cognitive and linguistic development. Further, she suggested that the research would benefit from a study of input to compare whether use of causatives in the children's language reflected what they actually heard in the input.

\section{Greenlandic}

As mentioned above, West Greenlandic is a highly polysynthetic language with a very rich and complex morphophonology. Words can have numerous derivational affixes, and also have obligatory inflectional endings, with complex attachment patterns. Fortescue's (1984) study of West Greenlandic was a pilot study with data from one child (aged 2;3) as a first step in analyzing morphological development in Greenlandic Eskimo. Fortescue and Lennert Olsen (1992) used data collected by the latter from children between 2;2 and 5;2 to explore how the children acquired all the basic parameters of this morphology during this period. In summarizing their findings, Fortescue and Lennert Olsen argued that children during this period move from single-morpheme utterances, which address specific pragmatic functions (such as hunger or rejection, e.g. peerit 'go away'), to the acquisition of new affixes, which they hypothesize are acquired initially in fixed familiar contexts, and then productively used in other known contexts. For example, a child, L, aged 2;2 extends the use of takkuut 'look' across contexts:

(5) ttakkuuk anner-punga ${ }^{6}$

look hurt-1SG.INDIC

'Look I've hurt myself'

(6) ttakkuuk nakuu-vunga

look hurt-1SG.INDIC

'Look I'm strong'

Children begin acquiring this complex morphology very early, and Fortescue and Lennert Olsen (1992) argued that it may be the very combinatorial flexibility of the complex morphology that assists with this, together with the very clear cut distinction 'between referring expressions (with distinctive nominal endings) and action/state expressions (with distinctive verbal endings), irrespective of the internal complexity of the expressions themselves' (p. 215). They noted that the complexity of the morphophonemic system must challenge the child's memory, and pointed out that adults, unless specifically trained, are generally unable to isolate bound morphemes.

\subsubsection{Bantu Languages}

The study of the acquisition of Bantu languages has largely been driven by the work of Katherine Demuth whose work has focused on Sesotho (Demuth 1998; Demuth and Ellis 2009). While Bantu languages share several typological characteristics, Demuth (2003) highlighted differences in the ordering of nominal morphology and agreement and overall acquisition order, as well as identifying several gaps in the research to date. More recently, Deen $(2005,2006)$ has examined the acquisition of Swahili.

\section{Swahili}

Deen's $(2005,2006)$ research into the acquisition of Swahili forms the basis for one of the most detailed analyses of the acquisition of a morphologically complex language. Deen 
studied four children (aged 1;8-3;2) and examined the early acquisition of inflection including subject and object agreement, mood, and tense prefixes. Deen (2005) examined the data of two of these children, one between the ages of 1;8 and 2;2 and the other between the ages of 2;10 and 3;0, recorded fortnightly. In this study, Deen examined subject agreement. Swahili allows subject noun phrases to be omitted, and so subjects were identified by context, with unclear cases excluded. Of over 400 subject agreements found across the two children, only 6 were incorrect. He argued that the fact that the agreements occurred correctly over a range of different verbs, which also showed alternations in agreement, suggests that, even at 1;8, the children must have an abstract rule operating.

Of particular interest for researchers investigating polysynthetic languages are his investigations into object agreement and nominal specificity. Object agreement in Swahili is obligatory when the object is specific but is prohibited when the object is non-specific. Deen (2006) showed that children overwhelmingly provide object agreement in obligatory contexts when the object is a personal name, is topicalized, or refers to first/second person. An example can be seen in (7) by a child aged 2;8;25, in which we see first person singular object agreement.

(7) ә-li-ni-chap-a

SA3s-past-OA1s-slap-IND

'She slapped me'

(Deen 2006: 235)

Deen (2006) argued that this cannot be due to a general strategy of overusing agreement, since object agreement never occurs in contexts which are prohibited in the adult target language, and this pattern was found at all stages in the data, where the youngest child was aged $1 ; 10$.

\section{Sesotho}

Sesotho is a southern Bantu language which, like other Bantu languages, has a complex inflectional system. The language has a noun class system in which the nominal stem is invariant, and has a set of singular/plural class prefixes with inflectional agreement associated with each noun phrase, and generally phonologically related to the noun class marker. The verbal complex encodes subject/object marking, tense/aspect and grammatical marking of functions such as passive, applicative, causative, and reflexive (Demuth 1992). Demuth's (1989, 1992, 1998, 2003) long-term research on Sesotho has largely come from her longitudinal spontaneous language recordings of four children in Lesotho, aged around 2;1-4;7. In general, Demuth has shown that Sesotho learners are able to master complex grammatical constructions such as passives and relative clauses at an early age compared to English learners, with the spontaneous and creative production of passives, relative clauses, and left dislocated constructions before the age of three. In her study of applicatives, Demuth (1998) examined two children's spontaneous speech interactions at ages $2 ; 1-2 ; 6$ and 3;0-3;2 and showed that by $2 ; 6$, children were using the applicative and related arguments productively as opposed to unanalyzed frozen forms. One example of this can be seen in the children's recasting of earlier utterances, which are not exact repetitions of earlier forms, as seen in the following Sesotho examples:

(8) mmatele (n-ngwath-el-e)

OBJ-feed-APL-FV

'Feed me something' 
(9)

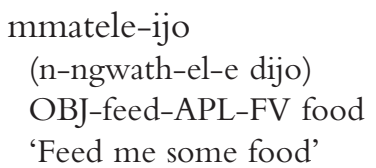

(Demuth 1998:793)

She argued (Demuth 1992) that Sesotho children's early acquisition of structures for which grammatical, cognitive, or maturational reasons are normally provided for their later acquisition in Indo-European languages points to the need for additional cross-linguistic research to determine whether differences in the acquisition of these constructions are grammatically driven (i.e. a similar acquisition order is found, for example, in other Bantu languages such as Zulu) or cognitive/maturational, which might result from frequency, or other effects.

\subsection{HOOKS TO LEARNING}

We can see throughout this survey of polysynthetic language acquisition that for those languages where the identification of roots or stems is relatively easy, there are similarities in the acquisition process. Data from Quiché Mayan and Mohawk suggest that children learning these languages initially produce the most perceptually prominent units of speech and continue to rely on perceptual salience until the morphology is finally discovered. Although children learning Navajo, Inuktitut, Quechua, and Tzeltal initially produce bare roots, which are not always the most perceptually prominent units in these languages, perceptual salience appears to also play an important role in helping the child identify these units. Initial productions consisting entirely of bare roots appear to occur only in languages in which there is some regular perceptual property that enables the consistent identification of the roots in the input. It may be that a major piece of the puzzle is missing here, that is the degree of fusion; in agglutinating languages, it is very likely to be easier to identify syllablesized morphemes than those which are not, and more difficult again where they are part of highly fused complexes. ${ }^{8}$

On the basis of Xanthos et al.'s (2012) research, which compared languages of varying morphological richness, it would appear to be the case that children's acquisition of languages which exhibit morphologically rich inflectional systems, correlates with the relative morphological richness of that language. Xanthos et al.'s (2012) cross-linguistic study compared the longitudinal acquisition of nine children from nine different language backgrounds with varying degrees of morphological complexity using a mean size of paradigm index, where paradigmatic richness 'refers to the tendency of a language to have a large number of formally distinct inflected word-forms per lemma' (2012, p. 464). Using this new measure, they concluded that there is a strong correlation between the morphological complexity of the input and the speed with which children acquire the morphological richness of the language (see Xanthos et al. 2012 for detail).

This suggests that it is not necessarily the case that greater morphological complexity leads to a more challenging task for the child. In fact, it appears to be the case that the more morphology there is in a language, and therefore the more morphology the child receives in the input, the more rapidly the child acquires the morphology. This suggests that frequency may override morphological complexity in the acquisition process.

\section{Conclusion}

Although there is still much research to be done in the acquisition of polysynthetic languages, the existing literature reveals a number of interesting findings which contribute to our 
current understanding of the role of salience, impact of language type, and morphological complexity.

Firstly, the research suggests that a lot more work is needed in the area of perceptual salience to determine whether it is a primary factor driving early acquisition of polysynthetic languages. Courtney and Saville-Troike (2002) suggested that morphological factors drive the acquisition of Quechua and Navajo, with roots/stems being extracted in early verb forms irrespective of their perceptual salience. This raises the interesting question of what children do when the root/stem is discontinuous in the verbal word, as in the Australian language Murrinh-Patha (Nordlinger 2010). ${ }^{9}$

Secondly, morphological complexity does not always lead to acquisitional complexity. In fact, Xanthos et al.'s (2012) study suggests that the more morphologically rich the language, the easier the morphology is to acquire. This concurs with Demuth's (e.g. 1992) research showing the early acquisition of causatives and applicatives by Sesotho children. Such findings suggest that the relevant factor for acquisition may not be morphological complexity, but morphological regularity. Polysynthetic languages contain words with many morphemes, and expressing complex grammatical concepts, but may be relatively regular in the templatic sequence in which they are used.

Following from these above two points, on the basis of the study of these languages, it is not clear what the role of 'chunking' (storing unanalyzed exemplars or chunks) may play in the acquisition of polysynthetic languages. Researchers have suggested that children store their early uses as unanalyzed amalgams or chunks. These would be attested at the stage where the child stores whole units before having analyzed the unit into its smaller components. Peters (1983, 1985), Pinker (1989) and Slobin (1985) argued that the child extracts entire utterances from the speech stream before beginning the process of segmentation. If children do this, we would expect to find learners of languages with complex distributed morphology to be producing ungrammatical unanalyzed chunks on the basis of the speech context - a finding that does not appear strongly in the literature. In fact, Rose and Brittain (2011) have suggested that such chunking plays a relatively minor role in the acquisition of Northern East Cree as merely the first step in order for the child to perform further grammatical analysis. It remains to be seen what the role of chunking is in other synthetic and polysynthetic languages.

Finally, studies such as Xanthos et al. (2012) demonstrate the role that input may play in understanding children's acquisition of complex morphology, highlighting the need for input-based research as well as acquisition-based research of the type discussed here.

\section{Short Biographies}

Barbara Kelly is a lecturer in Linguistics at the University of Melbourne. She obtained her $\mathrm{PhD}$ from the University of California, Santa Barbara, focusing on infant non-verbal communication. During this time, she lived and worked in the Himalayas and wrote the first grammar and glossary of Sherpa, a Tibetan language. Prior to commencing at University of Melbourne, she held a teaching position at Stanford University and has also worked in the Social Computing group at IBM and in cross-linguistic name development. Barbara's research and publications focus primarily on first language acquisition, in particular, how language-internal grammatical pressures interact with social pressures in children's socialization toward becoming competent language users.

Gillian Wigglesworth is the director of the Research Unit on Indigenous Language and a professor of Linguistics and Applied Linguistics at the University of Melbourne. She obtained her PhD from La Trobe University, Melbourne, and has worked extensively in first and 
second language acquisition and bilingualism. Her major research focus is on language use in remote indigenous communities. In particular, she is interested in the complex multilingual input many indigenous children receive from their caregivers and the languages that indigenous children are learning both at home and school. She has published extensively, including Bilingualism (Routledge 2007 with Ng Bee Chin), and has edited a wide variety of books including Children's language and multilingualism: Indigenous language use at home and school (Continuum 2008 with Jane Simpson).

Rachel Nordlinger is an associate professor in Linguistics at the University of Melbourne, where she returned after completing her PhD at Stanford University, USA, in 1997. Rachel's research centers around the description and documentation of Australia's indigenous languages, working with the Bilinarra, Wambaya, Gudanji, Murrinh-Patha, and Marringarr communities to record and preserve their traditional languages. She has also published on syntactic and morphological theory and, in particular, the challenges posed by the complex grammatical structures of Australian Aboriginal languages. She is the author of numerous articles and four books, including A Grammar of Wambaya (Pacific Linguistics, 1998) and Constructive Case: Evidence from Australian languages (CSLI Publications, 1998).

Joe Blythe is an interactional linguist with field experience in Australian Aboriginal languages. In 2009, he completed his PhD at the University of Sydney on person reference in the Australian polysynthetic language Murrinh-Patha. He has recently joined the University of Melbourne as an ARC DECRA fellow where he researches Murrinh-Patha language use in face-to-face conversational interaction and the acquisition of kinship categories. His interests include referential processes, preference organization, requests, repair, prosody, kinship and kinbased morphosyntax, and the evolution of language.

\footnotetext{
Notes

* Correspondence address: Rachel Nordlinger, School of Languages and Linguistics, University of Melbourne, VIC 3010, Australia. E-mail: racheln@unimelb.edu.au

1 Thanks to our anonymous reviewers for extensive comments on earlier versions of this paper, and to Debbie Loakes for early research help. This work was supported by the Australian Research Council grant DP110100961 "From little things, big things grow: how children learn a morphological complex Australian indigenous language" (CIs Wigglesworth, Nordlinger, Kelly, Blythe).

2 This and other related questions form the focus of our current project researching the acquisition of Murrinh-Patha, a polysynthetic language of northern Australia (Australian Research Council grant DP110100961 "From little things, big things grow: how children learn a morphological complex Australian indigenous language" (CIs Wigglesworth, Nordlinger, Kelly, Blythe)). For details of the project see http://languages-linguistics.unimelb.edu.au/projects/lamp.

3 Not all polysynthetic languages exhibit fusion though all exhibit considerable agglutination. Because 'agglutinating' languages have relatively high word-to-morpheme ratios, they are also relevant to researchers concerned with the acquisition of complex morphology.

4 Although, not unproblematic (see Bauer 2003: 232ff).

5 We are grateful to an anonymous reviewer for comments in relation to this.

6 Throughout the paper, children's ages are given as follows: 2;1 $=2$ years 1 month of age.

7 punga for consonant-final roots, vunga for vowel-final roots

8 Although not defined in Demuth 1998, it is assumed on the basis of the translation that FV is final vowel: mood.

9 We are grateful to one of our anonymous reviewers for this insight.
}

\section{Works Cited}

Allen, S. E. M. 1995. Acquisition of causatives in Inuktitut. Proceedings of the 27th annual Stanford child language research forum, ed. by E. V. Clark, 51-60. Stanford: CSLI.

- 1996. Aspects of argument structure acquisition in Inuktitut. Amsterdam: John Benjamins. 
1998. Categories within the verb category: learning the causative in Inuktitut. Linguistics 36(4) 633-77.

2007. Interacting pragmatic influences on children's argument realization. Crosslinguistic perspectives on argument structure: implications for learnability, ed. by M. Bowerman and P. Brown, 191-210. Mahwah, NJ: Erlbaum.

Allen, S. E. M., and M. B. Crago. 1992. First language acquisition of Inuktitut. Inuit studies occasional papers 4: proceedings of the seventh Inuit studies conference, ed. by M.-J. Dufour and F. Thérien, 273-81. Quebec: Association Inuksiutiit Katimajit.

Allen, S. E. M., and H. Schröder. 2003. Preferred argument structure in early Inuktitut spontaneous speech data. Preferred argument structure: grammar as architecture for function, ed. by J. W. Du Bois, L. E. Kumpf and W. J. Ashby, 301-38. Amsterdam: John Benjamins.

Bauer, L. 2003. Introducing Morphology. 2nd Edition. Edinburgh: Edinburgh University Press.

Baker, M. 1996. The polysynthesis parameter. Oxford Studies in Comparative Syntax. New York: Oxford University Press.

—. 2001. The atoms of language: the mind's hidden rules of grammar. New York: Basic Books.

Bloom, P. 2000. How children learn the meanings of words. Cambridge, MA: MIT Press.

Brittain, J., C. Dyck, Y. Rose, and M. MacKenzie. 2007. The Chisasibi child language acquisition study (CCLAS): a progress report. Papers of the thirty eighth Algonquian conference, ed. by H. C. Wolfart, 1-17. Winnipeg: University of Manitoba.

Brown, R. 1973. A first language: the early stages. Cambridge, MA: Harvard University Press.

Brown, P. 1998. Children's first verbs in Tzeltal: evidence for an early verb category, ed. by E. Lieven. Linguistics (Special edition) 36(4) 713-53.

Carey, S. 1978. The child as word learner. Linguistic theory and psychological reality, ed. by J. Bresnan, G. Miller and M. Halle, 264-93. Cambridge, MA: MIT Press.

Courtney, E. H., and M. Saville-Troike. 2002. Learning to construct verbs in Navajo and Quechua. Journal of Child Language 29. 623-54.

Crago, M. B., and S. E. M. Allen. 1998. Acquiring inuktitut. Language acquisition across North America: cross-cultural and crosslinguistic perspectives, ed. by O. Taylor and L. Leonard, 245-79. San Diego, CA: Singular Publishing Company.

Deen, K. U. 2005. Productive agreement in Swahili: against a Piecemeal Approach. The proceedings to the 29th Boston University Conference on language development, ed. by A. Brugos, M. Clark-Cotton and S. Ha, 156-67. Somerville, MA: Cascadilla Press.

- 2006. Object agreement and specificity in early Swahili. Journal of Child Language 33(2) 223-46.

Demuth, K. 1989. Maturation and the acquisition of the Sesotho passive. Language 65(1) 56-80.

- 1992. Acquisition of Sesotho. The cross-linguistic study of language acquisition, vol. 3, ed. by D. Slobin, 557-638. Hillsdale, NJ: Lawrence Erlbaum.

1998. Argument structure and the acquisition of Sesotho applicatives. Linguistics 36(4) 781-806.

2003. The acquisition of Bantu languages. The Bantu languages, ed. by D. Nurse and G. Phillipson, 209-22. Surry, UK: Curzon Press.

— and D. Ellis. 2009. Revisiting the acquisition of Sesotho noun class prefixes. Crosslinguistic approaches to the psychology of language: Festschrift for Dan Slobin, ed. by J. Guo, E. Lieven, N. Budwig, S. Ervin-Tripp, K. Nakamura and S. Özçali kan, 131-48. Hillsdale, NJ: Lawrence Erlbaum.

de Jong, K., M. E. Beckman, and J. Edwards. 1993. The interplay between prosodic structure and coarticulation. Language and Speech 36. 197-212.

Evans, N., and S. Levinson. 2009. The myth of language universals: language diversity and its importance for cognitive science. Behavioral and Brain Sciences 32. 429-92.

Evans, N., and H.-J. Sasse. 2002. Introduction: problems of polysynthesis. Problems of polysynthesis, Studia typologica 4, ed. by N. Evans and H.-J. Sasse, 1-13. Berlin: Akademie-Verlag.

Fortescue, M. 1984. West Greenlandic. Beckenham, Kent: Croom Helm.

1985. Learning to speak Greenlandic: a case study of a two-year-old's morphology in a polysynthetic language. First Language 5. 101-14.

Fortescue, M., and L. Lennert Olsen. 1992. The acquisition of West Greenlandic. The crosslinguistic study of language acquisition, vol. 3, ed. by D. I. Slobin, 111-220. Hillsdale, NJ: Lawrence Erlbaum.

Gleitman, L. 1990. Structural sources of verb learning. Language Acquisition 1. 1-63.

Kelly, B., R. Nordlinger, and G. Wigglesworth. 2010. Indigenous perspectives on the vitality of Murrinh-Patha. Proceedings of the ALS 2009 Conference, La Trobe University.

Larsen-Freeman, D. 2007. Reflecting on the cognitive-social debate in second language acquisition. The Modern Language Journal 91. 773-87.

Leonard L., K. McGregor, and G. Allen. 1992. Grammatical morphology and speech perception in children with specific language impairment. Journal of Speech and Hearing Research 35. 1076-85

Mithun, M. 1989. The acquisition of polysynthesis. Journal of Child Language 16. 285-312. 
Nordlinger, R. 2010. Verbal morphology in Murrinh-Patha: evidence for templates. Morphology 20(2) $321-41$.

Peters, A. M. 1983. The units of language acquisition. Cambridge, England: CUP.

- 1985. Language segmentation: operating principles for the perception and analysis of language. The crosslinguistic study of language acquisition, vol 2, ed. by D. I. Slobin, 1029-67. Hillsdale, NJ: Lawrence Erlbaum.

Peters, A. 1997. Language typology, prosody and the acquisition of grammatical morphemes. The crosslinguistic study of language acquisition, vol. 5, ed. by D. I. Slobin, 137-97. Hillsdale, NJ: Lawrence Erlbaum.

Pinker, S. 1989. Learnability and cognition. Cambridge, MA: MIT Press.

Pye, C. 1980. The acquisition of person markers in Quiché Mayan. Papers and Reports on Child Language Development 24. 115-22. Stanford, CA.

- 1992. The acquisition of K'iche' Maya. The crosslinguistic study of language acquisition, vol. 3, ed. by D. I. Slobin, 221-308. Hillsdale, NJ: Lawrence Erlbaum.

Rice, S., G. Libben, and B. Derwing. 2002. Morphological representation in an endangered, polysynthetic language. Brain \& Language Apr-Jun; 81(1-3) 473-86.

Rose, Y., and J. Brittain. 2011. Grammar matters: evidence from phonological and morphological development in Northern East Cree. Selected proceedings of the $4^{\text {th }}$ conference on Generative Approaches to Language Acquisition North America (GALANA 2010), ed. by M. Pirvulescu, M. C. Cuervo, A. Pérez-Leroux, J. Steele and N. Strik, $193-208$.

Slobin, D. I. (ed.) 1985. The crosslinguistic study of language acquisition, vol. 1. Hillsdale, NJ: Lawrence Erlbaum.

Strömqvist, S., and H. Ragnarsdóttir. 2000. On the acquisition of verb argument structure. Linguistics 38(3) $523-43$.

Terry, K. 2010. The emergence of intransitive inflection in Northern East Cree: a case study. MA Thesis, Memorial University of Newfoundland, Canada.

Tomasello, M. 2000. The social-pragmatic theory of word learning. Pragmatics 10(4) 401-13.

Upper, M., and M. McKay. 1987. Acquisition of Oji-Cree as a first language: a preliminary study of children's development, phase 1. Toronto: Ontario Ministry of Education.

. 1988. Acquisition of Oji-Cree as a first language: a preliminary study of children's development, phase 1 supplementary report. Toronto: Ontario Ministry of Education.

Xanthos, A., S. Lahaa, S. Gillis, U. Stefany, A. Aksu-Koc, A. Christofidou, N. Gagarina, G. Hrzica, F. Nihan Ketrez, M. Kilani-Schoch, K. Korecky-Kroll, M. Kovacevic, K. Laalo, M. Palmovic, B. Pfeiler, M. D. Voeikova, and W. U. Dressler. 2012. On the role of morphological richness in the early development of noun and verb inflection. First Language 31(4) 461-79. 